Check for updates

Cite this: Chem. Sci., 2018, 9, 3494

\title{
Pentacyclic adenine: a versatile and exceptionally bright fluorescent DNA base analogue $\uparrow$
}

\author{
Mattias Bood, (D) $\ddagger^{\mathrm{a}}$ Anders F. Füchtbauer, (D) $\mathrm{f}^{\mathrm{b}}$ Moa S. Wranne, (DD ${ }^{\mathrm{b}}$ Jong Jin Ro, ${ }^{\mathrm{f}}$ \\ Sangamesh Sarangamath, ${ }^{b}$ Afaf H. El-Sagheer, (D) c Déborah L. M. Rupert, ${ }^{\text {h }}$ \\ Rachel S. Fisher, ${ }^{\mathrm{e}}$ Steven W. Magennis, (D) Anita C. Jones, ${ }^{\mathrm{e}}$ Fredrik Höök, (DD ${ }^{\mathrm{h}}$ \\ Tom Brown, (D) ${ }^{9}$ Byeang Hyean Kim, (D) Anders Dahlén, ${ }^{f}$ L. Marcus Wilhelmsson (D) *b \\ and Morten Grøtli $(\mathbb{D}$ *a
}

\begin{abstract}
Emissive base analogs are powerful tools for probing nucleic acids at the molecular level. Herein we describe the development and thorough characterization of pentacyclic adenine (pA), a versatile base analog with exceptional fluorescence properties. When incorporated into DNA, pA pairs selectively with thymine without perturbing the B-form structure and is among the brightest nucleobase analogs reported so far. Together with the recently established base analog acceptor $\mathrm{qA}_{\text {nitro, }} \mathrm{pA}$ allows accurate distance and orientation determination via Förster resonance energy transfer (FRET) measurements. The high brightness at emission wavelengths above $400 \mathrm{~nm}$ also makes it suitable for fluorescence microscopy, as demonstrated by imaging of single liposomal constructs coated with cholesterolanchored pA-dsDNA, using total internal reflection fluorescence microscopy. Finally, pA is also highly promising for two-photon excitation at $780 \mathrm{~nm}$, with a brightness (5.3 GM) that is unprecedented for a base analog.
\end{abstract}

Received 23rd December 2017

Accepted 1st March 2018

DOI: $10.1039 / \mathrm{c} 7 \mathrm{sc0} 05448 \mathrm{c}$

rsc.li/chemical-science fluorophores, e.g. lower bulkiness, possibility of labelling close to a site of interest, lower interference during interaction between the nucleic acid and other molecules and higher precision in position as well as orientation. FBAs have been used successfully for microenvironment sensing and have become powerful tools for studying the structure and dynamics of nucleic acids. ${ }^{1-5}$ Recent developments include a thymidine mimic used for site-specific metal binding in dsDNA, ${ }^{6,7}$ a tricyclic cytidine analogue with a turn-on response to duplex formation, ${ }^{\mathbf{8}}$ isomorphic emissive RNA derivatives, ${ }^{\mathbf{9}, \mathbf{1 0}}$ a novel quadracyclic adenosine Förster resonance energy transfer (FRET) pair ${ }^{11}$ and an emissive interbase FRET pair. ${ }^{12}$

Generally, the incorporation of FBAs into oligonucleotides results in a significant decrease in fluorescence intensity, even more so upon hybridization to complementary strands. For example, the brightness of 2-aminopurine (2-AP, Chart 1) drops almost 100-fold upon incorporation in dsDNA. ${ }^{16,17}$ However, with a few exceptions (e.g. tC, ${ }^{\mathbf{1 3 , 1 4}} \mathrm{tC}^{\mathrm{O}},{ }^{15} \mathrm{qAN} 1,{ }^{11}$ Chart 1 ), quantum yields and normal (one-photon) brightness values of FBAs inside oligonucleotides are characterized only for a few sequence contexts, which limits a comparison between them (for a detailed comparison of one- and two-photon emissive properties of FBAs, see Table 1). A few probes essentially retain $\left(\mathrm{tC}^{\mathrm{O}}\right)$ or even exhibit enhanced fluorescence quantum yield and brightness (e.g. tC and ${ }^{\mathrm{DMA}} \mathrm{C}$, Chart 1) in dsDNA. ${ }^{\mathbf{1 3 , 1 4 , 1 8}}$ Still, these fluorophores are significantly less bright than the most commonly used external fluorophores (Cy-, Alexa-, ATTO-dyes). 
<smiles>[R]n1cnc2cnc(N)nc21</smiles>
2-AP<smiles>[R]On1c(=O)nc(N)c2cc(N(C)C)ccc21</smiles>
${ }^{\mathrm{DMA}} \mathrm{C}$<smiles>[R]n1cc2c3c(ncnc31)Nc1ccc([N+](=O)[O-])cc1-2</smiles><smiles>[X]c1ccccc1Nc1nc(=O)n([R])cc1[X]</smiles>

$\mathrm{tC}: \mathrm{X}=\mathrm{S}$ $\mathrm{tC}^{\mathrm{O}}: \mathrm{X}=\mathrm{O}$
qA<smiles>[R]n1cc2c3c(ncnc31)Nc1ccccc1-2</smiles><smiles>[R]n1c(=O)c(C)nc2c(=O)[nH]c(N)nc21</smiles><smiles>[R]n1c(=O)c(C)nc2c(N)ncnc21</smiles>

6MAP

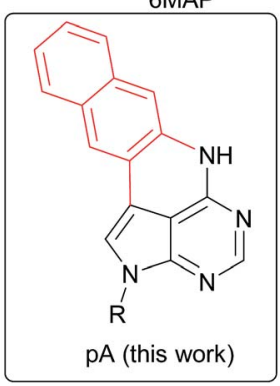

Chart 1 Structure of 2-AP, tC, tC, qAN1, ${ }^{\mathrm{DMA}} \mathrm{C}, 6-\mathrm{MI}, 6 \mathrm{GAP}, \mathrm{qA}$, $\mathrm{qA}_{\text {nitro }}$ and $\mathrm{pA}$. $\mathrm{R}$ denotes the sugar-phosphate backbone. Atoms of extended adenine (with $\mathrm{N}-7$ replaced with $\mathrm{C}$ ) are shown in red.

For detailed real-time information on the structure and intrinsic dynamics of nucleic acids, ${ }^{19,20}$ as well as their subcellular or cellular location, FBAs with a lower detection limit would be advantageous. In particular, FBAs that are bright enough, and sufficiently resistant to photobleaching, are required for single-molecule studies and super-resolution imaging. ${ }^{21}$ A few groups have investigated single-molecule detection of FBAs, however, with limited success. For example, 3-MI monomers were shown by fluorescence correlation spectroscopy to have a brightness of $4 \mathrm{kHz}$ per molecule and a signal-to-background (S/B) of 5, whereas the values for 3MI-containing oligonucleotides were reduced by a factor of $4 .^{22}$

Recently, there has been a growing interest in the use of twophoton absorption processes in combination with FBAs. Ultraviolet light $(<400 \mathrm{~nm})$, which is normally required to excite FBAs, is prone to cause photobleaching, generate high levels of background fluorescence and damage biological samples. ${ }^{23}$ These problems can be avoided by the use of two-photon excitation. The near-infrared light used for this process can reduce out-of-focus photobleaching and autofluorescence, in turn allowing deeper tissue penetration, and increased threedimensional resolution. ${ }^{24}$

Overall, the number of FBAs investigated for two-photon excitation purposes is scarce. Among the established FBAs, 6MI and 6MAP (Chart 1) have the highest two-photon absorption cross-sections (Table 1). ${ }^{25,26}$ Recently, the two-photon-induced fluorescence properties of several new uridine FBAs $\left(e . g .{ }^{\text {th }} \mathrm{U}\right.$, TPAU and ADQ, Table 1) have been studied. ${ }^{27}$ TPAU has the highest two-photon cross-section reported so far for a FBA (7.6 $\mathrm{GM}$ at $690 \mathrm{~nm}$ ). However, it has a very low quantum yield (1\%), resulting in a low two-photon brightness (two-photon crosssection $\times$ quantum yield). 6-MI therefore remains the FBA with the highest reported two-photon brightness (Table 1), but its quantum yield is reduced significantly inside base stacks (for

Table 1 Photophysical properties of pA (this work) and previously reported FBAs ${ }^{a}$

\begin{tabular}{|c|c|c|c|c|c|c|c|c|}
\hline \multirow[b]{3}{*}{ Name } & \multicolumn{5}{|c|}{ One-photon excitation } & \multicolumn{3}{|c|}{ Two-photon excitation $^{b}$} \\
\hline & \multirow[b]{2}{*}{$\lambda_{\mathrm{Abs}}(\mathrm{nm})$} & \multirow[b]{2}{*}{$\lambda_{\mathrm{Em}}(\mathrm{nm})$} & \multirow[b]{2}{*}{$\Phi_{\mathrm{F}}^{c}(\%)$} & \multicolumn{2}{|c|}{$\begin{array}{l}\text { Brightness, } \varepsilon \Phi_{\mathrm{F}} \\
\left(\mathrm{M}^{-1} \mathrm{~cm}^{-1}\right)\end{array}$} & \multirow[b]{2}{*}{$\lambda_{\mathrm{Ex}}(\mathrm{nm})$} & \multirow[b]{2}{*}{$\sigma^{2 c}(\mathrm{GM})$} & \multirow[b]{2}{*}{$\Phi_{\mathrm{F}} \sigma^{2}(\mathrm{GM})^{d}$} \\
\hline & & & & Monomer & $\mathrm{dsDNA}^{e}$ & & & \\
\hline $\mathrm{pA}$ & 387 & 420 & 66 & 10100 & 1400 & 780 & 6.6 & 5.3 \\
\hline $6 \mathrm{MAP}^{22,26}$ & 330 & 430 & 39 & 3300 & 150 & 659 & $3.4^{25}$ & 1.3 \\
\hline $2-\mathrm{AP}^{16,17}$ & 303 & 370 & 68 & 4080 & 50 & 584 & $0.2^{23}$ & 0.14 \\
\hline $8-v^{4} A^{40}$ & 290 & 382 & 65 & 8200 & 200 & n.d. & n.d. & n.d. \\
\hline $\mathrm{tC}^{13,14}$ & 377 & 513 & 13 & 520 & 760 & 800 & $1.5^{h 23}$ & 0.32 \\
\hline $\mathrm{tC}^{\mathrm{O} 15}$ & 360 & 465 & 30 & 2700 & 2000 & n.d. & n.d. & n.d. \\
\hline $\mathrm{FDT}^{18}$ & 316 & 434 & 3 & 330 & n.d. & 690 & $2.1^{27}$ & 0.063 \\
\hline $\mathrm{ADQ}^{45}$ & 316 & 363 & 4 & 470 & n.d. & 690 & $1.8^{27}$ & 0.070 \\
\hline
\end{tabular}

${ }^{a}$ For structures and names see Chart S1. ${ }^{b}$ Two-photon excitation determined for FBA monomers. ${ }^{c}$ Quantum yield determined in various buffered water solutions at either $\mathrm{pH} 7.0$ or $\mathrm{pH} 7.5$ (top 8 entries) or deionized water (bottom 6 entries). ${ }^{d}$ Goeppert-Mayer units, $1 \mathrm{GM}^{c} 10^{-50} \mathrm{~cm}^{4} \mathrm{~s}$ per photon. ${ }^{e}$ Average over various DNA sequence surroundings. However, in some cases only one sequence was reported. ${ }^{f}$ Values from ongoing studies (manuscript in preparation). ${ }^{g}$ The molar absorptivity has not been reported, but is estimated to $12000 \mathrm{M}^{-1} \mathrm{~cm}^{-1} .{ }^{46} h$ Measured in the sequence $5^{\prime}$-AATCTCACAGC(tC)TGATCACATTGCTA- $-3{ }^{\prime} .{ }^{i}$ Quantum yield based on ${ }^{\text {th }} \mathrm{dT}$ dsDNA $(2.7 \%)$ in the sequence $5^{\prime}-\mathrm{GCGCGA}\left({ }^{\text {th }} \mathrm{dT}\right) \mathrm{A}\left({ }^{\text {th }} \mathrm{dT}\right)$ $\mathrm{A}\left({ }^{\mathrm{th}} \mathrm{dT}\right) \mathrm{AgGAGC}-3^{\prime}{ }^{41}$ 
a purine-rich and a pyrimidine-rich sequence: $96 \%$ and $64 \%$ quenching, respectively), which hampers its use as a twophoton probe. ${ }^{28}$ While advances in recent years have brought the brightness of FBAs much closer to that of external fluorophores, there is still a significant need for the development of FBAs with even higher one-photon brightness and a significantly growing interest in FBAs with two-photon brightness values high enough for practical application as two-photon probes.

Herein, we report the synthesis and characterization of pentacyclic adenine, $\mathrm{pA}$, a bright and photophysically versatile fluorescent adenine analogue, and establish its usefulness for both (one-photon) FRET and two-photon purposes. Finally, pA is demonstrated to be a promising internal label for microscopy applications in a total internal reflection fluorescence (TIRF) microscopy study visualizing single liposome constructs coated with pA-containing DNA.

\section{Results and discussion}

\section{Design and synthesis of pA}

We have recently shown that the brightness of the promising quadracyclic adenine (qA) analogue, can be significantly improved by replacing the outer ring with a pyridine ring (Chart 1), and demonstrated the use of one of these analogues, qAN1 (Chart 1), for interbase FRET in dsDNA. ${ }^{11,29} \mathrm{~A}$ screen of pentacyclic adenine analogue motifs, wherein the outer ring of the quadracyclic scaffold is replaced with coumarins, quinolines and keto-functionalized naphthalenes (Chart S2 $\dagger$ ), was performed. After extensive synthetic efforts and photophysical characterization (data not shown), a non-substituted naphthalene scaffold (Chart 1, right) was found to have the most desirable photophysical properties.

The method developed for the preparation of qAN1 and $\mathrm{qA}_{\text {nitro }}$ was adopted for the synthesis of pA (1). ${ }^{11}$ The DMTrprotected phosphoramidite of pA (2, Scheme 1) was synthesized over 9 steps with an overall yield of $16 \%$, starting from the substituted deazapurine 3. Suzuki-Miyaura cross-coupling of compound $\mathbf{3}$ with 3-amino-2-iodo-naphtalene (6) furnished 3a, which was subjected to acetylation to activate the amine for nucleophilic aromatic substitution to yield $\mathbf{3 b}$. LiHMDSmediated intramolecular cyclization of $\mathbf{3 b}$ provided compound 4 in high yield. Subsequent Boc protection of the secondary amine, followed by removal of the $t$-butyldimethylsilyloxymethyl (TBDMSOM) protecting group using TBAF and ethylenediamine gave $\mathbf{5}$. Compound $\mathbf{5}$ was $\mathrm{N}$-glycosylated using Hoffer's $\alpha$-chloro-sugar (7), ${ }^{30}$ and after global deprotection, the pA monomer 1 was obtained in excellent yield. Subsequent DMTr-protection of the primary alcohol and phosphitylation of the secondary alcohol of 1 furnished the phosphoramidite building block 2 .

\section{Photophysical properties of the pA nucleoside}

The photophysical properties of the pA nucleoside (1) were determined in a variety of protic and aprotic solvents, covering a wide polarity range (Table 2 and Fig. 1).

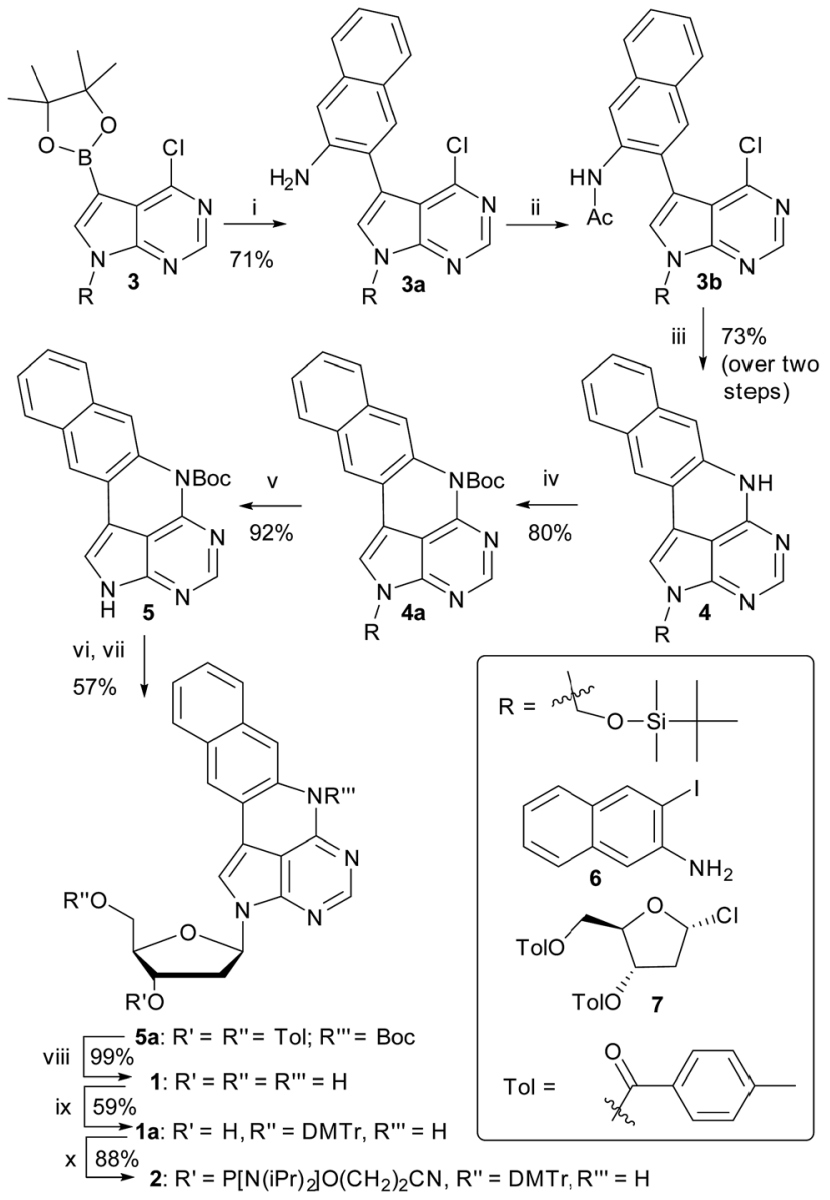

Scheme 1 Synthesis of the $\mathrm{pA}$ phosphoramidite. Reagents and conditions: (i) 6 (1 equiv.) $\mathrm{Pd}\left(\mathrm{PPh}_{3}\right)_{2} \mathrm{Cl}_{2}$ (4.4 mol\%), $\mathrm{K}_{2} \mathrm{CO}_{3}$ (2.5 equiv.), $\mathrm{MeCN} / \mathrm{H}_{2} \mathrm{O} 19: 1,80^{\circ} \mathrm{C}, 1.5 \mathrm{~h}$; (ii) $\mathrm{AcCl}$ (1.15 equiv.), Py (1.25 equiv.), $\mathrm{DCM}, 0{ }^{\circ} \mathrm{C}, 5 \mathrm{~min}$; then RT, $1 \mathrm{~h}$; (iii) LiHMDS (1.8 equiv.), THF, MW $\left(100{ }^{\circ} \mathrm{C}, 30 \mathrm{~min}\right.$ ); (iv) $\mathrm{Boc}_{2} \mathrm{O}$ (2.2 equiv.), DMAP (2.5 equiv.), THF, RT, $24 \mathrm{~h}$; (v) TBAF (1 equiv.), ethylenediamine (2 equiv.), THF, $0^{\circ} \mathrm{C}, 15 \mathrm{~min}$; (vi) $\mathrm{NaH}$ (1.35 equiv.), $\mathrm{MeCN}, 0{ }^{\circ} \mathrm{C}, 3 \mathrm{~h}$; (vii) 7 (1.2 equiv.), $0{ }^{\circ} \mathrm{C}, 10 \mathrm{~min}$; then RT, 2 h; (viii) $\mathrm{NaOMe}\left(6\right.$ equiv.), $\mathrm{MeCN}, 50^{\circ} \mathrm{C}, 20 \mathrm{~min}$; (ix) DMTr-Cl (1.3 equiv.), Py, $0^{\circ} \mathrm{C}, 5 \mathrm{~min}$; then $\mathrm{RT}, 1.5 \mathrm{~h}$; (x) chloro-(2-cyanoethoxy) diisopropylaminophosphine (2 equiv.), $\mathrm{N}$-methylmorpholine (4 equiv.), $\mathrm{CH}_{2} \mathrm{Cl}_{2}, \mathrm{RT}, 2 \mathrm{~h}$.

The absorption spectrum of the pA nucleoside in water is characterized by two peaks at 368 and $387 \mathrm{~nm}$, with molar absorptivities of 11400 and $15200 \mathrm{M}^{-1} \mathrm{~cm}^{-1}$, respectively, as well as a strong absorption peak at $292 \mathrm{~nm}$. In less polar solvents, these absorption peaks are slightly sharper with a redshift of up to $10 \mathrm{~nm}$. The emission spectrum of pA in water shows a single emission peak with a maximum at $420 \mathrm{~nm}$ (Fig. 1), whereas in less polar solvents a $20 \mathrm{~nm}$ red-shifted shoulder is visible. The largest Stokes shift, $33 \mathrm{~nm}$ (corresponding to $2000 \mathrm{~cm}^{-1}$ ), is observed in water.

Importantly, the pA nucleoside (1) retains an excellent fluorescence quantum yield across all solvents investigated $(64 \% \leq$ $\Phi_{\mathrm{F}} \leq 84 \%$, Table 2), resulting in brightness values of above $10000 \mathrm{M}^{-1} \mathrm{~cm}^{-1}$ in all solvents, and making it the brightest base analogue monomer reported to date (see Table 1). The quantum yield in water $(66 \%)$ is comparable to that of the 
Table 2 Photophysical properties of the pA nucleoside monomer (1) in different solvents

\begin{tabular}{|c|c|c|c|c|c|c|c|}
\hline Solvent & $\lambda_{\mathrm{Abs}, 1}(\mathrm{~nm})$ & $\varepsilon_{1}\left(\mathrm{M}^{-1} \mathrm{~cm}^{-1}\right)$ & $\lambda_{\mathrm{Abs}, 2}(\mathrm{~nm})$ & $\varepsilon_{2}\left(\mathrm{M}^{-1} \mathrm{~cm}^{-1}\right)$ & $\lambda_{\mathrm{Em}}(\mathrm{nm})$ & $\Phi_{\mathrm{F}}(\%)$ & $\varepsilon_{1} \Phi_{\mathrm{F}}^{a}\left(\mathrm{M}^{-1} \mathrm{~cm}^{-1}\right)$ \\
\hline Water $^{b}$ & 387 & 15200 & 368 & 11400 & 420 & 66 & 10100 \\
\hline DMSO & 396 & 17100 & 378 & 12500 & 421 & 84 & 14400 \\
\hline DCM & 392 & 16100 & 373 & 11700 & 410 & 74 & 11900 \\
\hline Toluene & 397 & 18700 & 377 & 13200 & 409 & 72 & 13400 \\
\hline $\mathrm{MeCN}$ & 390 & 16500 & 372 & 11900 & 414 & 64 & 10500 \\
\hline
\end{tabular}

${ }^{a}$ Brightness is calculated as the product of the fluorescence quantum yield $\left(\Phi_{\mathrm{F}}\right)$ and the molar absorptivity at the long-wavelength maximum $\left(\varepsilon_{1}\right)$. ${ }^{b}$ With $2 \%$ DMSO.

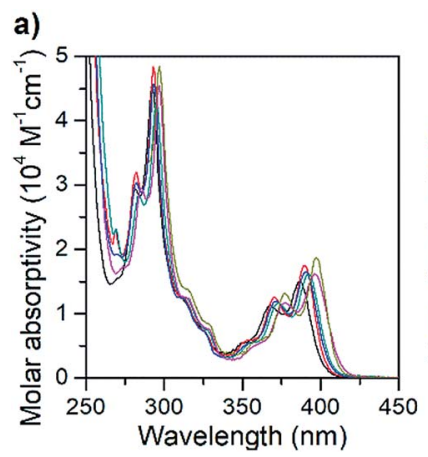

b)

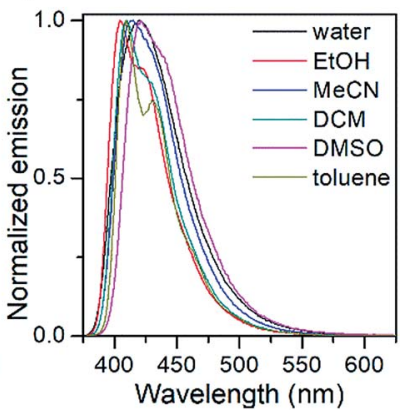

Fig. 1 Isotropic absorption spectra (a) and normalized fluorescence emission spectra (b) of the pA nucleoside monomer (1) in various solvents.

widely used 2-aminopurine (68\%), ${ }^{16}$ and is significantly higher than that of a majority of other bright FBAs found in the literature (for details see Table 1).

\section{Incorporation of pA into DNA oligonucleotides}

To study the effect of replacing adenine with the size-expanded pA on DNA structure and stability, as well as the sensitivity of the photophysical properties of pA to neighbouring bases, we synthesized 16 different pA-modified DNA decamer sequences (Table 3). These oligonucleotides cover all possible combinations of neighbouring bases to pA. Stepwise coupling efficiencies were determined by automated trityl cation conductivity monitoring and exceeded $98 \%$ for all oligonucleotides synthesized, including oligonucleotides containing pA. For details of the solid-phase oligonucleotide synthesis, see the ESI.†

\section{Conformation and stability of pA-modified duplexes}

Circular dichroism (CD) analysis of the 16 strands annealed with their complementary strands shows the archetypal characteristics of B-form DNA, a positive band between 260 and $280 \mathrm{~nm}$ and a negative band around $245 \mathrm{~nm}$ (Fig. S1 and S2†), indicating that duplexes modified with pA adopt normal B-form geometry. ${ }^{31}$ There are minor differences between CD-spectra of the modified and unmodified duplexes, which most likely stem from differences in the absorption spectra of pA and adenine. In a similar manner to the quadracyclic adenine analogues qA and
Table 3 Melting temperatures of $\mathrm{pA}$-modified duplexes $\left(T_{\mathrm{m}}^{\mathrm{pA}}\right)$, unmodified duplexes $\left(T_{\mathrm{m}}^{\mathrm{A}}\right)$, and the difference $\left(\Delta T_{\mathrm{m}}\right)$ between them

\begin{tabular}{|c|c|c|c|c|}
\hline $\mathrm{NN}^{a}$ & Sequence & $T_{\mathrm{m}}^{\mathrm{pA}}\left({ }^{\circ} \mathrm{C}\right)$ & $T_{\mathrm{m}}^{\mathrm{A}}\left({ }^{\circ} \mathrm{C}\right)$ & $\Delta T_{\mathrm{m}}\left({ }^{\circ} \mathrm{C}\right)$ \\
\hline $\mathrm{AA}$ & $5^{\prime}$-d(CGCAA(pA)ATCG)-3' & 40.8 & 43.5 & -2.7 \\
\hline $\mathrm{AC}$ & $5^{\prime}-\mathrm{d}(\mathrm{CGCAA}(\mathrm{pA}) \mathbf{C T C G})-3^{\prime}$ & 45.3 & 47.1 & -1.8 \\
\hline AG & $5^{\prime}-\mathrm{d}(\mathrm{CGCAA}(\mathrm{pA}) \mathbf{G T C G})-3^{\prime}$ & 42.4 & 45.9 & -3.5 \\
\hline AT & $5^{\prime}-\mathrm{d}(\mathrm{CGCAA}(\mathrm{pA}) \mathbf{T T C G})-3^{\prime}$ & 44.8 & 43.4 & 1.4 \\
\hline $\mathrm{CA}$ & $5^{\prime}-\mathrm{d}(\mathrm{CGCAC}(\mathrm{pA}) \mathrm{ATCG})-3^{\prime}$ & 49.9 & 46.5 & 3.4 \\
\hline $\mathrm{CC}$ & $5^{\prime}-\mathrm{d}(\mathrm{CGCAC}(\mathrm{pA}) \mathbf{C T C G})-3^{\prime}$ & 54.6 & 50.3 & 4.3 \\
\hline CG & $5^{\prime}-\mathrm{d}(\mathrm{CGCAC}(\mathrm{pA}) \mathrm{GTCG})-3^{\prime}$ & 52.2 & 49.5 & 2.7 \\
\hline $\mathrm{CT}$ & $5^{\prime}-\mathrm{d}(\mathrm{CGCAC}(\mathrm{pA}) \mathbf{T T C G})-3^{\prime}$ & 53.2 & 47.3 & 5.9 \\
\hline GA & $5^{\prime}-\mathrm{d}(\mathrm{CGCAG}(\mathrm{pA}) \mathbf{A T C G})-3^{\prime}$ & 43.0 & 45.3 & -2.3 \\
\hline GC & $5^{\prime}-\mathrm{d}(\mathrm{CGCAG}(\mathrm{pA}) \mathbf{C T C G})-3^{\prime}$ & 48.4 & 49.2 & -0.8 \\
\hline GG & $5^{\prime}$-d(CGCAG(pA)GTCG)-3' & 47.6 & 48.1 & -0.5 \\
\hline GT & $5^{\prime}-\mathrm{d}(\mathrm{CGCAG}(\mathrm{pA}) \mathbf{T T C G})-3^{\prime}$ & 46.4 & 45.4 & 1.0 \\
\hline TA & $5^{\prime}-\mathrm{d}(\mathrm{CGCAT}$ (pA)ATCG)-3' & 43.0 & 41.1 & 1.9 \\
\hline TC & $5^{\prime}-\mathrm{d}(\mathrm{CGCAT}(\mathrm{pA}) \mathbf{C T C G})-3^{\prime}$ & 46.1 & 43.7 & 2.4 \\
\hline TG & $5^{\prime}-\mathrm{d}(\mathrm{CGCAT}(\mathrm{pA}) \mathbf{G T C G})-3^{\prime}$ & 45.3 & 43.6 & 1.7 \\
\hline TT & $5^{\prime}-\mathrm{d}(\mathrm{CGCAT}(\mathrm{pA}) \mathbf{T T C G})-3^{\prime}$ & 45.8 & 40.6 & 5.2 \\
\hline
\end{tabular}

${ }^{a}$ Sequences are named by the bases neighbouring pA on the $5^{\prime}$ - and $3^{\prime}$ sides, respectively. Unmodified samples contain an adenine instead of pA. Duplexes were formed by hybridization with the complementary strand as described in the experimental section (see ESI). The melting temperatures were calculated as the maximum of the first derivative of the UV-melting curves with a standard error of $\leq 0.3{ }^{\circ} \mathrm{C}$. For individual error values, see Table S1.

qAN1, the long-wavelength absorption band of pA was not observed in any of the CD-spectra. ${ }^{11,32}$

To investigate the effect of pA-incorporation on the stability of DNA duplexes, the melting temperatures of all pA-modified and unmodified duplexes were measured (Table 3). The UVmelting curves of all pA-modified duplexes (data not shown) have the general shape of the corresponding unmodified duplex, strongly indicating that normal B-form DNA is formed when adenine is replaced with pA. On average, pA-incorporation increases the DNA duplex melting temperature, $T_{\mathrm{m}}$, by $1.1^{\circ} \mathrm{C}$, a significantly smaller change than that of the quadracyclic adenine analogs qA $\left(3.0^{\circ} \mathrm{C}\right)^{32}$ and qAN1 $\left(2.9^{\circ} \mathrm{C}\right) .{ }^{11}$ Overall, pA with a $5^{\prime}$-purine neighbour has a destabilizing effect, while a $5^{\prime}$ pyrimidine or a $3^{\prime}$-thymine neighbour has a stabilizing effect. This observation is in line with the results for both qA and qAN1, which have been attributed to the larger increase in basestacking overlap that occurs between the extended ring system of qA/qAN1 and a $5^{\prime}$-pyrimidine compared to a $5^{\prime}$-purine. ${ }^{11,32}$ 
Due to the correlation between thermal stability of the DNA duplex and neighbouring bases, the user can fine-tune the relative melting temperatures of pA-modified duplexes as compared to their unmodified counterparts. The small overall increase in melting temperature of pA-DNA is generally preferable over other adenine FBAs such as $2-\mathrm{AP},{ }^{33} 3-\mathrm{MI},{ }^{28} 6 \mathrm{MAP}$, DMAP,${ }^{34}$ and $x A,{ }^{35}$ which reduce the duplex stability.

The base-pairing specificity of pA was evaluated by the change in melting temperature upon annealing three sequences (CT, GA and TA, see Table 3) with complementary sequences containing mismatched adenine, cytosine or guanine opposite pA (Fig. 2 and Table $\mathrm{S} 2 \dagger$ ).

The sequences were chosen to investigate the influence of neighbouring pyrimidines (CT), purines (GA) or one of each (TA). The melting temperature decreases by 2.6 to $10.8^{\circ} \mathrm{C}$ when a base other than thymine is opposite pA, indicating that $\mathrm{pA}$ is selective for thymine. Unlike the parent compound $\mathrm{qA}$ and qAN1, where the smallest decrease was observed for guanine and adenine mismatches, respectively (qA: avg. for G: $9.8^{\circ} \mathrm{C} v s$. 15.3 ${ }^{\circ} \mathrm{C}$ for A/C; qAN1: avg. for A: $6.3{ }^{\circ} \mathrm{C} v s .10 .2{ }^{\circ} \mathrm{C}$ for $\left.\mathrm{C} / \mathrm{G}\right),{ }^{11,32}$ the decrease is smallest when $\mathrm{pA}$ is opposite a cytosine and between two purines (GA). A possible explanation for this is that the extended aromatic structure of pA makes it easier to stack efficiently with its neighbouring bases while accommodating the mismatch. In that case, the bicyclic purines would offer a more efficient stacking than monocyclic pyrimidine neighbours, while the cytosine mismatch may be more easily accommodated than the larger purines.

\section{Photophysical properties of pA in SSDNA and dsDNA}

The absorption and emission properties of pA in single- and double-stranded DNA were measured for all 16 combinations of neighbouring bases (Table 4 and Fig. S3†). Fig. 3 shows representative absorption and emission spectra of pA in ssDNA and dsDNA. The absorption maximum of pA is slightly red-shifted when incorporated into DNA, and, importantly for its utility, lies well outside the absorption range of the natural nucleobases $(390 \pm 2 \mathrm{~nm}$ for all sequences in single- and doublestranded DNA), allowing selective excitation. ${ }^{36}$ The emission

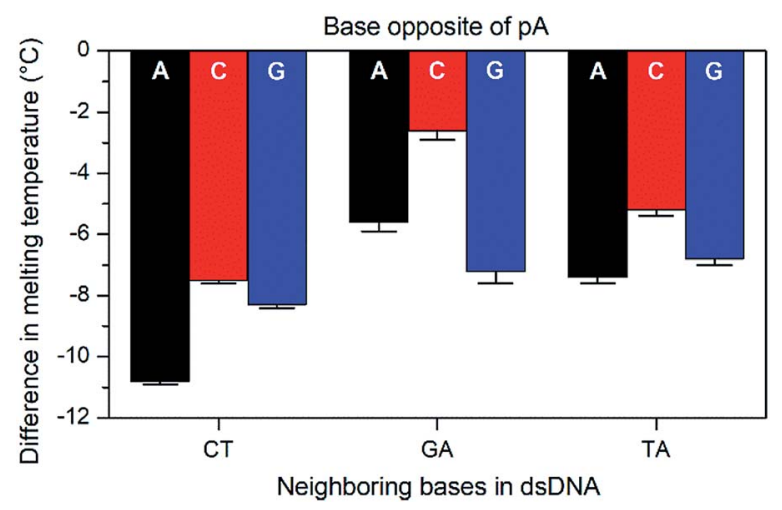

Fig. 2 Difference in $T_{m}$ with standard error between mismatched (A, $C$, or $G$ opposite $p A$ ) and the corresponding matched sequences ( $T$ opposite $\mathrm{pA}$ ) for three sets of $\mathrm{pA}$ nearest neighbours (CT, GA, and TA). peak of pA is blue-shifted upon incorporation in DNA to around $407 \mathrm{~nm}$ for ssDNA and $403 \mathrm{~nm}$ for dsDNA, compared to $420 \mathrm{~nm}$ for the monomer, but still lies in the visible region. This blueshift is typical for FBAs inside nucleic acids, and is due to the less polar environment inside DNA which leads to reduced solvent relaxation. ${ }^{37}$

Both the absorption and emission are more structured inside DNA, indicating that pA is firmly stacked and protected from aqueous solvation. One additional advantage of $\mathrm{pA}$ over qAN1 in future applications is that unlike qAN1, none of the pA duplexes have an additional shoulder in their emission spectrum (Fig. S3†), indicating that for pA, no significant tautomerization occurs in the excited state. ${ }^{11}$

The quantum yield of pA inside dsDNA is significantly higher than that of qAN1, reported to be one of the brightest adenine FBAs in DNA (Tables 1 and 4). ${ }^{11}$ On average, the fluorescence quantum yield of $\mathrm{pA}$ is $15 \%$ in ssDNA and $10 \%$ in dsDNA (Table 4 , Fig. S4 $\dagger)$, resulting in average brightness $\left(\varepsilon \times \Phi_{\mathrm{F}}\right)$ values of $2130 \mathrm{M}^{-1} \mathrm{~cm}^{-1}$ and $1370 \mathrm{M}^{-1} \mathrm{~cm}^{-1}$, respectively. This represents a 2.7-fold increase in average brightness in dsDNA compared with qAN1 and ranks pA top three among characterized FBAs (Table 1; also note that 6-MI has been studied for only a few sequences).

The quantum yield of pA is dependent on the neighbouring bases (Table 4, Fig. S4 $\dagger$ ), and is lowest when pA is flanked by pyrimidines in sSDNA or by a $5^{\prime}$-cytosine in dsDNA, the latter being the only instance where qAN1 has a higher quantum yield than pA (Fig. S5 $\dagger$ ).

Apart from sequence GT, all sequences with a neighbouring thymine show a higher quantum yield in dsDNA than in ssDNA. The same trend was noted for qAN1, and was attributed to reduced stacking interaction between thymine and qAN1 in the helical duplex structure. ${ }^{11}$ The quantum yield is highest when pA is flanked by purines, especially adenine which yields unprecedented FBA brightness values (for comparison see Table 4) of $8400 \mathrm{M}^{-1} \mathrm{~cm}^{-1}$ and $3000 \mathrm{M}^{-1} \mathrm{~cm}^{-1}$ in $\operatorname{ssDNA}\left(\Phi_{\mathrm{F}}=\right.$ $58 \%)$ and dsDNA ( $\left.\Phi_{\mathrm{F}}=22 \%\right)$, respectively, which is even higher than the top values for $\mathrm{tC}^{\mathrm{O}}$ (having the highest average brightness, Table 1). Inside DNA, the decrease in quantum yield of pA is accompanied by a shortening of its fluorescence lifetime, with amplitude-weighted mean lifetimes in dsDNA ranging from $3.4 \mathrm{~ns}$ for sequence AA to $0.7 \mathrm{~ns}$ for GC (Table $\mathrm{S} 3 ; \dagger$ detailed lifetime analysis manuscript is in preparation).

\section{pA in interbase FRET}

The emission of pA overlaps well with the absorption of the FRET-acceptor $\mathrm{qA}_{\text {nitro }}$ (Fig. 4) ${ }^{\mathbf{1 1}}$ with a calculated Förster radius, $R_{0}$, of 21-28 $\AA$ (average 24.4 $\AA$ ), indicating that the FRET pair could be used to monitor distances slightly beyond 1.5 turns of the B-DNA helix. ${ }^{38}$ In the $R_{0}$ calculations, the orientation factor, $\kappa^{2}$, was set to $2 / 3$ for comparative purposes, but for firmly stacked probes in DNA, the value of $\kappa^{2}$ is expected to vary with the relative orientation of the donor and acceptor, which depends on the number of bases separating them. ${ }^{11,38}$

To evaluate the FRET efficiency of the $\mathrm{pA}-\mathrm{qA}_{\text {nitro }}$ pair at various donor-acceptor distances, eight 33-mer sequences were 
Table 4 Photophysical properties of single- and double-stranded DNA sequences containing pA

\begin{tabular}{|c|c|c|c|c|c|c|c|c|}
\hline $\mathrm{NN}^{a}$ & \multicolumn{4}{|l|}{ Single strands } & \multicolumn{4}{|l|}{ Double strands } \\
\hline $\mathrm{AC}$ & 15000 & 406 & 11 & 1700 & 14300 & 402 & 6.2 & 890 \\
\hline AG & 15200 & 405 & 24 & 3600 & 13200 & 403 & 16 & 2100 \\
\hline AT & 15000 & 407 & 15 & 2300 & 14500 & 400 & 17 & 2500 \\
\hline CG & 14700 & 405 & 6.1 & 900 & 12400 & 406 & 8.2 & 1000 \\
\hline CT & 14000 & 409 & 4.1 & 570 & 13500 & 403 & 10 & 1400 \\
\hline GA & 15000 & 407 & 42 & 6300 & 14000 & 404 & 14 & 2000 \\
\hline GC & 16000 & 404 & 4.4 & 700 & 14700 & 405 & 3.4 & 500 \\
\hline GG & 14300 & 406 & 28 & 4000 & 13200 & 405 & 13 & 1700 \\
\hline GT & 15200 & 407 & 8.3 & 1300 & 14400 & 401 & 7.7 & 1100 \\
\hline
\end{tabular}

${ }^{a}$ Sequences are named according to nucleotides surrounding pA; full sequences can be found in Table $3 .{ }^{b}$ Molar absorptivity values are reported as an average of two or more experiments with a standard error of $\leq 200{ }^{c}{ }^{c}$ Quantum yields were determined for the emission profiles shown in Fig. S3, with quinine sulfate as reference $\left(\Phi_{\mathrm{F}}=54.6 \%\right.$ in $\left.0.5 \mathrm{M} \mathrm{H}_{2} \mathrm{SO}_{4}\right)$, using an excitation wavelength of $353 \mathrm{~nm}$, and are reported as an average of two or more experiments with a standard error of $\leq 0.8 \%$.

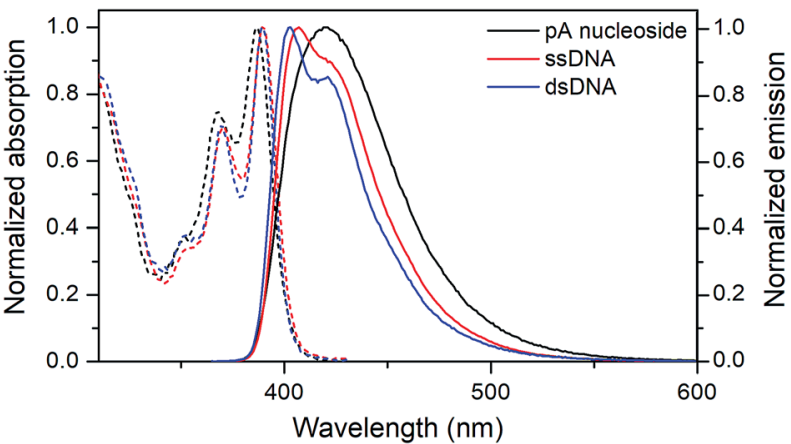

Fig. 3 Normalized absorption (dashed) and emission (solid) spectra of the $\mathrm{pA}$ nucleoside ( 1 , black), and of the $\mathrm{pA}$-containing sequence $\mathrm{AA}$ (Table 3 ) as single- (red) and double-stranded (blue) DNA.

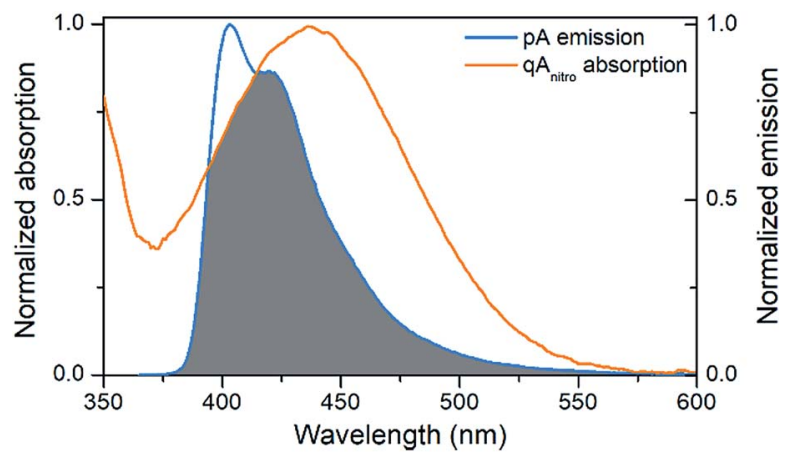

Fig. 4 Visualization of the spectral overlap between pA emission and $\mathrm{qA}_{\text {nitro }}$ absorption in dsDNA. Spectra are normalized at their longwavelength maxima. prepared (Table 5): three donor strands containing pA (all with adenine neighbours), four complementary acceptor strands containing $\mathrm{qA}_{\text {nitro, }}$ and one unmodified complementary strand. First, the quantum yields of pA at the three donor positions were measured in duplexes without acceptor. The quantum yield was found to depend on position, increasing (from 20 to $28 \%$ ) as pA is positioned further from the $5^{\prime}$-end. A similar trend was observed for qAN1 in the same sequences, and may be due to changes in the local environment at each position. The FRET efficiency of each 12 combinations of the donor and acceptor sequences, corresponding to a separation of 2-13 base-pairs, was determined using both the decrease in steady-state emission and the shortening of the average lifetime of pA (see Fig. 5 and Table S4 $\dagger$ ).

Table 5 Synthesized 33-mer sequences used for interbase FRET measurements

\begin{tabular}{|c|c|c|}
\hline Sequence name ${ }^{a}$ & DNA sequence ${ }^{b}$ & $\Phi_{\mathrm{F}}^{c}(\%)$ \\
\hline D7 & $5^{\prime}-\mathrm{d}($ CGA TCA (pA)AA AAA ATT $\mathbf{w})-3^{\prime}$ & 20 \\
\hline D9 & $5^{\prime}-\mathrm{d}(\mathrm{CGA}$ TCA AA(pA) AAA ATT $\mathbf{w})-3^{\prime}$ & 24 \\
\hline D11 & $5^{\prime}-\mathrm{d}($ CGA TCA AAA A(pA)A ATT $\mathbf{w})-3^{\prime}$ & 28 \\
\hline A0 & $5^{\prime}-\mathrm{d}(\mathbf{X}$ TAT AAT CGT AAT TTT $\mathbf{Z})-3^{\prime}$ & \\
\hline A13 & $5^{\prime}-\mathrm{d}\left(\mathbf{X}\right.$ TAT $\mathbf{q} \mathbf{A}_{\text {nitro }}$ AT CGT AAT TTT $\left.\mathbf{Z}\right)-3^{\prime}$ & \\
\hline A14 & $5^{\prime}-\mathrm{d}\left(\mathbf{X}\right.$ TAT A $\mathbf{q A} \mathbf{A}_{\text {nitro }}$ T CGT AAT TTT $\left.\mathbf{Z}\right)-3^{\prime}$ & \\
\hline A19 & $5^{\prime}-\mathrm{d}\left(\mathbf{X}\right.$ TAT AAT CGT $\mathbf{q} \mathbf{A}_{\text {nitro }}$ AT TTT $\left.\mathbf{Z}\right)-3^{\prime}$ & \\
\hline $\mathrm{A} 20$ & $5^{\prime}-\mathrm{d}\left(\mathbf{X}\right.$ TAT AAT CGT A $\mathbf{q} \mathbf{A}_{\text {nitro }}$ T TTT $\left.\mathbf{Z}\right)-3^{\prime}$ & \\
\hline
\end{tabular}

${ }^{a}$ Sequence and sample preparation can be found in the ESI. Samples are named by the donor (D) or acceptor (A) position from the $5^{\prime}$ end. ${ }^{b} \mathbf{W}=$ ACG ATT ATA AGG AGG AGG. $\mathbf{X}=$ CCT CCT CCT; $\mathbf{Z}=$ TTT TGA TCG. ${ }^{c}$ Quantum yields were determined with quinine sulfate as reference $\left(\Phi_{\mathrm{F}}=54.6 \%\right.$ in $\left.0.5 \mathrm{M} \mathrm{H}_{2} \mathrm{SO}_{4}\right)$ using an excitation wavelength of $353 \mathrm{~nm}$. 


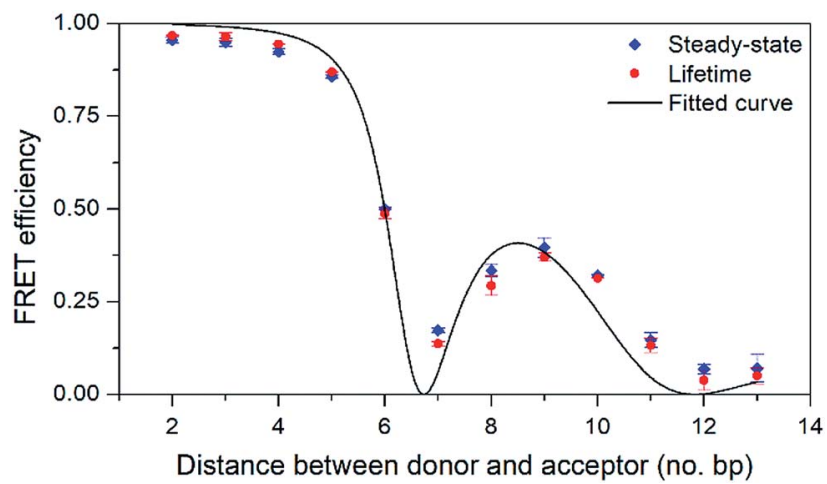

Fig. 5 FRET efficiency with 95\% confidence intervals as a function of the number of base pairs separating the donor (pA) and acceptor $\left(q A_{n i t r o}\right)$. Diamonds and circles mark data from steady-state and lifetime measurements, respectively. The line shows the curve fitted to the data based on FRET-theory (eqn (S9) †).

As can be seen in Fig. 5, the FRET efficiency is high at short distances, but varies periodically as the donor-acceptor distance increases, which indicates that $\mathrm{pA}$ and $\mathrm{qA}_{\text {nitro }}$ are firmly stacked inside DNA. An in-house designed MATLAB script was used to fit a function based on FRET-theory to the data (see eqn (S9) $\dagger$ ). The optimal fit is obtained for an overlap integral of $1.8 \times 10^{14} \mathrm{M}^{-1} \mathrm{~cm}^{-1} \mathrm{~nm},{ }^{4}$ and a phase angle of $43^{\circ}$ (the angle between the donor and acceptor transition dipole moment projected onto the base-pair plane, when donor and acceptor are in adjacent base pairs). ${ }^{38}$ Using the spectral profiles of $\mathrm{pA}$ and $\mathrm{qA}_{\text {nitro }}$, the overlap integral was calculated to be $1.5 \times$ $10^{14} \mathrm{M}^{-1} \mathrm{~cm}^{-1} \mathrm{~nm},{ }^{4}$ which is indeed close to the fitted value. Using time-dependent density functional theory (TDDFT)calculations, the orientation of the transition dipole moments of $\mathrm{pA}$ and $\mathrm{qA}_{\text {nitro }}$ have been predicted, and suggests an associated phase angle of $43^{\circ}$ in B-form DNA, which is also in good agreement with the fitted value (experimental determination of the transition dipole moments of $\mathrm{pA}$ and $\mathrm{qA}_{\text {nitro }}$ is the subject of a separate study; manuscript in preparation). In summary, pA is an excellent FRET donor that surpasses qAN1 in brightness and allows for base-base FRET-studies at longer distances than qAN1.

\section{pA as a two-photon chromophore}

Based on its exceptionally high one-photon brightness for an FBA, we anticipated that pA might have a potential as twophoton probe. Two-photon excitation at $780 \mathrm{~nm}$ was verified by measuring the fluorescence intensity as a function of laser power (Fig. 6). The log-log plot shows a slope of $2.00( \pm 0.05)$, confirming a two-photon process. The two-photon cross-section of the pA base at $780 \mathrm{~nm}$ was measured to be $6.6 \mathrm{GM}$ (Table S5 $\dagger$ ), which combined with its high quantum yield makes the twophoton brightness, $\Phi_{\mathrm{F}} \sigma^{2}=5.3 \mathrm{GM}$, significantly higher than 5-(thiophen-2-yl)-6-aza-uridine, TPAU $\left(\Phi_{\mathrm{F}} \sigma^{2}=0.76 \mathrm{GM}\right.$ for $690 \mathrm{~nm}$ excitation, Table 1 ; Chart $\mathrm{S} 1 \dagger$ for structure), and the pteridines 6-MI and 6MAP $\left(\Phi_{\mathrm{F}} \sigma^{2}=1.75\right.$ and $1.33 \mathrm{GM}$, respectively, Table 1; Chart 1 for structure), which are the brightest two-photon excitable FBAs reported to date (Table 1). ${ }^{27}$

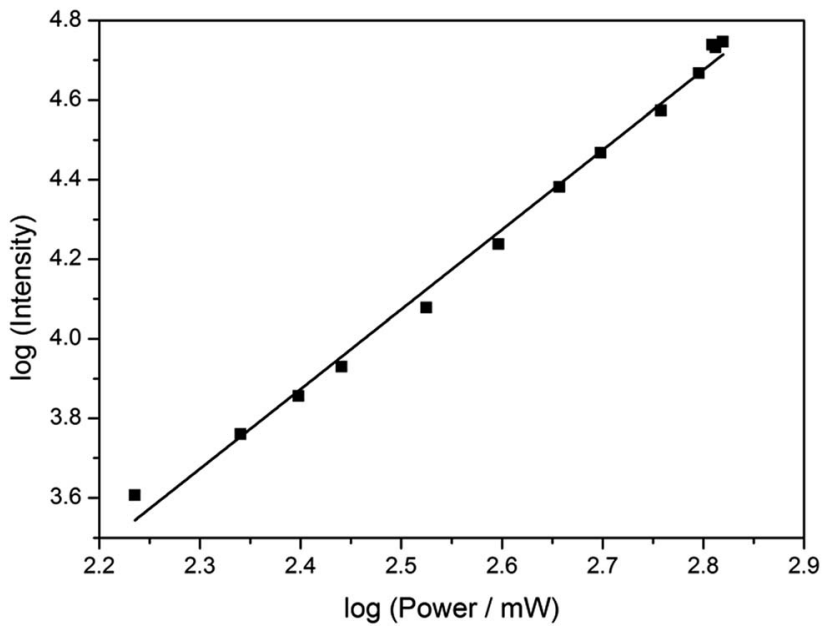

Fig. 6 Plot of log (fluorescence intensity) vs. log (laser power) for pA in $\mathrm{EtOH}$, showing a square-law dependence. The excitation wavelength was $780 \mathrm{~nm}$. The errors were calculated to $<5 \%$ from the standard deviation of three emission spectra collected at each power.

Importantly, the excitation wavelength of $780 \mathrm{~nm}$ for $\mathrm{pA}$ is also ideal for conventional Ti-sapphire laser excitation. When incorporated into an oligonucleotide (Table 3, sequence GA), the two-photon cross section was measured as 3.0 GM in SSDNA and 2.4 GM in dsDNA of this sequence, yielding highly promising FBA two-photon brightness values of $1.3 \mathrm{GM}$ and $0.35 \mathrm{GM}$ in sSDNA and dsDNA, respectively (Tables S6 and S7 $\dagger$ ).

The two-photon brightness of pA is significantly higher than that of other FBAs (Table 1), in general more than an order of magnitude. Moreover, pA keeps a high two-photon cross section inside DNA and is similar to that of coumarine-120 (cross section of $3 \mathrm{GM}$ in water), which has been detected previously at the single-molecule level. ${ }^{47}$ We therefore hypothesize that pA may become the first practical single-molecule FBA probe. Overall, the two-photon properties of pA as a monomer and inside DNA are unmatched by previous FBAs and, in combination with its excellent one-photon emissive properties, this makes pA is a highly versatile fluorophore for biological purposes.

\section{pA in single-particle microscopy}

The superior brightness of pA compared with other FBAs opens possibilities for its use as a fluorescent label in microscopy applications. To test this we used the general features of a liposome-DNA construct already established in-house. ${ }^{48}$ In this preliminary study, liposomes decorated with double cholesterol-anchored dsDNA binding five AA pA-sequences (Table 3; adenine-flanked pA) through a 50-mer overhang containing $5 \times 10$-mer repeats of the complementary sequence, were observed using TIRF microscopy (Fig. 7; for details of sample preparation, sequences of the anchoring cholesterol DNAs, and microscopy setup see ESI $\dagger$ ). Even though adenineflanked pA is approximately 24 times less bright than the membrane-attached Rhodamine $\mathrm{B}\left(\varepsilon \times \Phi_{\mathrm{F}}=68900 \mathrm{M}^{-1} \mathrm{~cm}^{-1}\right)$, and at most 2.5 times more abundant than rhodamine in the 

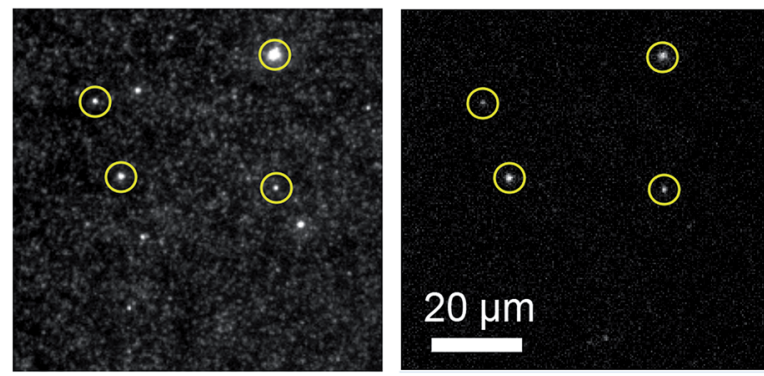

Fig. 7 TIRF images of liposome systems labelled with Rhodamine Bconjugated lipids and cholesterol-anchored pA-modified dsDNA. Left: visualization by excitation of Rhodamine $B$ using a TRITC filter. Right: visualization of the same liposomes by exciting pA using a DAPI filter.

liposome constructs (details in ESI $\dagger$ ), it is still possible to visualize the same liposome systems by exciting pA (circles in Fig. 7, left and right). This serves as an example that pA indeed can be used for visualization purposes in microscopy studies at concentrations comparable to those of commercially available fluorophores. In contrast to FBAs, such fluorophores are commonly used to externally label DNA using covalent linkers at the end of the sequences. Our proof-of-concept experiment shows the possibility of using FBAs in microscopy-based investigations of nucleic acids, for example, monitoring and tracking of DNA/RNA in live cells. Compared to the external labels our novel FBA offers some important advantages. For example, pA can be placed directly into the duplex close to a site of interest without perturbing the DNA structure, where it can serve as a sensitive and spatially fixed probe. Moreover, external probes with their combined hydrophobic and charged properties are prone to interact with lipids of liposomal, lipid nanoparticle (LNP) and cell membrane systems, whereas this is considerably less likely for $\mathrm{pA}$, and other FBAs, which are hidden away in the interior of the nucleic acid sequence. We suggest that this will be advantageous in, for example, microscopy investigations of uptake, trafficking, delivery and release of nucleic acid-based drug candidates formulated in lipid-based systems.

\section{Conclusions}

Fluorescent base analogues offer important advantages over extrinsic probes, but due to the current slight shortcomings in photophysical properties they have yet to achieve the wide applicability of conventional linker-coupled labels. In this work, we report a highly fluorescent adenine analogue, pA, that has exceptional one- and two-photon brightness as a monomer and, importantly, when incorporated into DNA. Despite its size, we find that pA seems to only minimally perturb B-form DNA and keep the sequence specificity of normal A. The photophysical properties of pA compare favourably with, or outperform, all previously reported fluorescent base analogues (Table 1 ). The versatility of $\mathrm{pA}$ is demonstrated through its use as a FRET donor, as a two-photon excitation probe, and as a bright label in microscopy, and we foresee its broad application. Furthermore, we hypothesize that pA may become the first practical single- molecule observable FBA using two-photon excitation methodology. We are currently exploring the possibility of using pA in single-molecule experiments to facilitate investigations of the structure and dynamics of oligonucleotides as well as their interactions with, for example, small molecules, peptides and proteins.

\section{Conflicts of interest}

There are no conflicts to declare.

\section{Acknowledgements}

This work was supported by the Swedish Foundation for Strategic Research (SSF, grants No. ID14-0036, IS14-0041 and IRC150065) and the Swedish Research Council (VR, grant No. 20134375). BHK thanks the support of NRF of South Korea (2014R1A2A1A12067404). AHE-S was supported by UK BBSRC grant BB/J001694/2. RSF gratefully acknowledges PhD studentship funding from the Engineering and Physical Sciences Research Council (UK).

\section{Notes and references}

1 W. Xu, K. M. Chan and E. T. Kool, Nat. Chem., 2017, 9, 1043.

2 A. Matarazzo and R. H. E. Hudson, Tetrahedron, 2015, 71, 1627.

3 L. M. Wilhelmsson, Q. Rev. Biophys., 2010, 43, 159.

4 R. W. Sinkeldam, N. J. Greco and Y. Tor, Chem. Rev., 2010, 110, 2579.

5 D. W. Dodd and R. H. E. Hudson, Mini-Rev. Org. Chem., 2009, $6,378$.

6 G. Mata, O. P. Schmidt and N. W. Luedtke, Chem. Commun., 2016, 52, 4718.

7 O. P. Schmidt, G. Mata and N. W. Luedtke, J. Am. Chem. Soc., 2016, 138, 14733.

8 D. D. Burns, K. L. Teppang, R. W. Lee, M. E. Lokensgard and B. W. Purse, J. Am. Chem. Soc., 2017, 139, 1372.

9 D. Shin, R. W. Sinkeldam and Y. Tor, J. Am. Chem. Soc., 2011, 133, 14912.

10 A. R. Rovira, A. Fin and Y. Tor, J. Am. Chem. Soc., 2015, 137, 14602.

11 M. S. Wranne, A. F. Füchtbauer, B. Dumat, M. Bood, A. H. ElSagheer, T. Brown, H. Gradén, M. Grøtli and L. M. Wilhelmsson, J. Am. Chem. Soc., 2017, 139, 9271.

12 J. H. Han, S. Yamamoto, S. Park and H. Sugiyama, Chem.Eur. J., 2017, 7607.

13 L. M. Wilhelmsson, P. Sandin, A. Holmén, B. Albinsson, P. Lincoln and B. Nordén, J. Phys. Chem. B, 2003, 107, 9094.

14 P. Sandin, L. M. Wilhelmsson, P. Lincoln, V. E. C. Powers, T. Brown and B. Albinsson, Nucleic Acids Res., 2005, 33, 5019. 15 P. Sandin, K. Börjesson, H. Li, J. Mårtensson, T. Brown, L. M. Wilhelmsson and B. Albinsson, Nucleic Acids Res., 2008, 36, 157.

16 D. C. Ward, E. Reich and L. Stryer, J. Biol. Chem., 1969, 244, 1228. 
17 E. L. Rachofsky, R. Osman and J. B. A. Ross, Biochemistry, 2001, 40, 946.

18 N. J. Greco and Y. Tor, J. Am. Chem. Soc., 2005, 127, 10784. 19 P. Tompa, Nat. Chem. Biol., 2012, 8, 597.

20 E. A. Dethoff, K. Petzold, J. Chugh, A. Casiano-Negroni and H. M. Al-Hashimi, Nature, 2012, 491, 724.

21 G. T. Dempsey, J. C. Vaughan, K. H. Chen, M. Bates and X. W. Zhuang, Nat. Methods, 2011, 8, 1027.

22 J. E. Sanabia, L. S. Goldner, P.-A. Lacaze and M. E. Hawkins, J. Phys. Chem. B, 2004, 108, 15293.

23 R. S. K. Lane and S. W. Magennis, RSC Adv., 2012, 2, 11397.

24 F. Helmchen and W. Denk, Nat. Methods, 2005, 2, 932.

25 R. J. Stanley, Z. Hou, A. Yang and M. E. Hawkins, J. Phys. Chem. B, 2005, 109, 3690.

26 M. E. Hawkins, Methods Enzymol., 2008, 450, 201.

27 R. S. K. Lane, R. Jones, R. W. Sinkeldam, Y. Tor and S. W. Magennis, ChemPhysChem, 2014, 15, 867.

28 M. E. Hawkins, W. Pfleiderer, F. M. Balis, D. Porter and J. R. Knutson, Anal. Biochem., 1997, 244, 86.

29 B. Dumat, M. Bood, M. S. Wranne, C. P. Lawson, A. F. Larsen, S. Preus, J. Streling, H. Gradén, E. Wellner, M. Grøtli and L. M. Wilhelmsson, Chem.-Eur. J., 2015, 21, 4039.

30 M. Hoffer, Chem. Ber., 1960, 93, 2777.

31 J. Kypr, I. Kejnovska, D. Renciuk and M. Vorlickova, Nucleic Acids Res., 2009, 37, 1713.

32 A. Dierckx, F.-A. Miannay, N. Ben Gaied, S. Preus, M. Björck, T. Brown and L. M. Wilhelmsson, Chem.-Eur. J., 2012, 18, 5987.

33 D. G. Xu, K. O. Evans and T. M. Nordlund, Biochemistry, 1994, 33, 9592.

34 M. E. Hawkins, Cell Biochem. Biophys., 2001, 34, 257.
35 J. Gao, H. Liu and E. T. Kool, J. Am. Chem. Soc., 2004, 126, 11826.

36 D. Onidas, D. Markovitsi, S. Marguet, A. Sharonov and T. Gustavsson, J. Phys. Chem. B, 2002, 106, 11367.

37 J. R. Lakowicz, Principles of Fluorescence Spectroscopy, Springer, US, 2007.

38 K. Börjesson, S. Preus, A. H. El-Sagheer, T. Brown, B. Albinsson and L. M. Wilhelmsson, J. Am. Chem. Soc., 2009, 131, 4288.

39 E. Katilius and N. W. T. Woodbury, J. Biomed. Opt., 2006, 11, 044004.

40 N. Ben Gaied, N. Glasser, N. Ramalanjaona, H. Beltz, P. Wolff, R. Marquet, A. Burger and Y. Mely, Nucleic Acids Res., 2005, 33, 1031.

41 G. Mata and N. W. Luedtke, J. Am. Chem. Soc., 2015, 137, 699. 42 V. Kilin, K. Gavvala, N. P. F. Barthes, B. Y. Michel, D. Shin, C. Boudier, O. Mauffret, V. Yashchuk, M. Mousli, M. Ruff, F. Granger, S. Eiler, C. Bronner, Y. Tor, A. Burger and Y. Mély, J. Am. Chem. Soc., 2017, 139, 2520.

43 I. Okamura, S. Park, R. Hiraga, S. Yamamoto and H. Sugiyama, Chem. Lett., 2017, 46, 245.

44 R. W. Sinkeldam, P. A. Hopkins and Y. Tor, ChemPhysChem, 2012, 13, 3350.

45 Y. Xie, T. Maxson and Y. Tor, Org. Biomol. Chem., 2010, 8, 5053.

46 K. Datta, N. P. Johnson, G. Villani, A. H. Marcus and P. H. von Hippel, Nucleic Acids Res., 2012, 40, 1191.

47 L. Brand, C. Eggeling, C. Zander, K. H. Drexhage and C. A. M. Seidel, J. Phys. Chem. A, 1997, 101, 4313-4321.

48 I. Pfeiffer and F. Höök, J. Am. Chem. Soc., 2004, 126, 1022410225. 